\title{
Determining fractal properties of soot aggregates and primary particle size distribution in counterflow flames up to $10 \mathrm{~atm}$
}

\author{
Hafiz M.F. Amin*, Anthony Bennett and William L. Roberts \\ Clean Combustion Research Center \\ King Abdullah University of Science and Technology \\ Thuwal 23955-6900, Saudi Arabia
}

\begin{abstract}
* Corresponding author:
Hafiz M. F. Amin

Clean Combustion Research Center

King Abdullah University of Science and Technology

Thuwal 23955-6900, Saudi Arabia
\end{abstract}

Email: hafiz.amin@kaust.edu.sa

Phone: +966 561502768

\section{Colloquium: SOOT, NANOMATERIALS, AND LARGE MOLECULES}

\section{Method of word count: Method 1}

Total Length of paper 6154

Word count

$\begin{array}{ll}\text { Main text } & 3102 \text { (by Microsoft Word count) } \\ \text { References } & 594 \text { (recommended algebraic expression) } \\ \text { Equations } & 106 \text { (recommended algebraic expression) } \\ \text { Tables } & 152 \text { (recommended algebraic expression) } \\ \text { Table 1 } & 91 \text { single column } \\ \text { Table 2 } & 61 \text { single column } \\ \text { Figures } & 2199 \text { (reduced to reproduction size and algebraic expression) } \\ \text { Figure 1 } & 156 \text { single column } \\ \text { Figure 2 } & 158 \text { single column } \\ \text { Figure 3 } & 368 \text { double column } \\ \text { Figure 4 } & 338 \text { double column } \\ \text { Figure 5 } & 487 \text { double column } \\ \text { Figure 6 } & 693 \text { double column } \\ & \\ \text { Abstract } & 209 \\ \text { Color page charges are not applicable }\end{array}$




\title{
Determining fractal properties of soot aggregates and primary particle size distribution in counterflow flames up to $10 \mathrm{~atm}$
}

\author{
Hafiz M.F. Amin*, Anthony Bennett and William L. Roberts \\ Clean Combustion Research Center \\ King Abdullah University of Science and Technology \\ Thuwal 23955-6900, Saudi Arabia
}

\begin{abstract}
Experimental investigations of soot morphology are performed in counterflow flames of $N_{2}$-diluted ethylene and air, up to 10 atm. A thermophoretic sampling device is attached to a pressure vessel containing a counterflow burner where flames with an ethylene mole fraction of 0.3 are stabilized at 3 , 5, and 6 atm. To allow measurements at higher pressures, the fuel mole fraction is lowered to 0.2 to reduce the soot loading and flames are studied at 5, 7, and $10 \mathrm{~atm}$. Thermophoretic sampling of the soot zone is performed using TEM grids. The sampling process causes minimal flame disturbances. Soot collected on TEM grids is analyzed under transmission electron microscope (TEM). Primary particle size distributions are inferred at each pressure by manually analyzing the primary particles from TEM images. Fractal properties of soot at each pressure are also obtained by analyzing the TEM images at comparatively low magnifications. Mean primary particle diameter increases from $17.5 \mathrm{~nm}$ to $47.1 \mathrm{~nm}$ as the pressure is increased from 3 to $10 \mathrm{~atm}$, whereas the fractal dimension and prefactor do not change with pressure up to $10 \mathrm{~atm}$. For the flames studied here, fractal dimension lies between 1.61 to 1.67 whereas fractal prefactor varies between 1.68 to 1.86 without following any apparent trend with pressure.
\end{abstract}

\section{Keywords}

Primary particle size, Soot morphology, Pressurized counterflow flame, Thermophoretic sampling 


\section{Introduction}

In the transportation sector, diesel engines and gas turbines are two main sources of power production. These hydrocarbon-based devices are operated at high pressure to increase the power output and efficiency. When operated at high pressure, the soot emissions also increase and these emissions are known to have negative effects on human health [1]. The ultimate impact of soot particles on human health depend on the soot morphology [2]. Soot emissions also contribute to environmental problems and the morphology of these carbonaceous particles is crucial for determining their life cycle and their influence on the radiative balance of earth [3]. In order to control soot emissions, it is important to understand soot formation and oxidation mechanisms, which require detailed information about chemical composition and morphological parameters of soot [4].

Soot morphology has been extensively studied in atmospheric flames, using both intrusive and non-intrusive diagnostics [5-7]. However, there are few studies that focus on the effects of pressure on soot morphology. A comprehensive detail of high pressure laminar flame studies is provided in [8]. To our knowledge, light scattering for the study of fractal properties of soot in pressurized flames has not been reported. However, Steinmetz et al. [9] measured the primary particle diameter in an ethylene air coflow flame using light scattering combined with an extinction technique and found that the primary particle size increased with pressure. Due to large uncertainties of associated measurements, the authors [9] recommended additional experimental work. Thomson et al. [10] applied laser-induced incandescence in pressurized methane air coflow flames and investigated the influence of pressure on effective particle size from 0.5 to $4.0 \mathrm{MPa}$. They found that the effective diameter increased dramatically with pressure, and this effective particle diameter does not represent the primary particle diameter because the shielding effect reduces conduction between the aggregated particles and surrounding gas that was not accounted for. 
Laser-based diagnostics have been successfully used for investigating soot particle size, but the associated diagnostic complications in a pressurized environment and the uncertainties associated with the optical properties of soot make them difficult to apply quantitatively. Thermophoretic sampling followed by transmission electron microscopy (TEM) analysis is an intrusive diagnostic that has been commonly used at atmospheric conditions but rarely performed in pressurized flames. Recently, Vargas et al. [11] designed and built a high pressure thermophoretic sampling system to investigate soot primary particle size using thermophoretic sampling and TEM analysis in a methane air coflow diffusion flame. They reported a decrease of the primary particle size by $35 \%$, as the pressure was increased from 2 to $10 \mathrm{~atm}$. One should note that all the investigations in pressurized flames discussed above are made in coflow flames, which are two-dimensional and computationally taxing for testing complex chemical mechanisms such as those involving soot formation/oxidation [12].

Counterflow flames are less susceptible to buoyancy-induced instabilities and can be studied numerically with modest computational power. Many researchers have used counterflow configuration at high pressure for investigating sooting flames [13-15] and studying flame extinction strain rates [16, 17]. Amin et al. [15] used light scattering and extinction technique to investigate the primary particle diameter and aggregate size of soot in a nitrogen-diluted ethylene air counterflow flame, from 2 to 5 atm [15]. They found that both particle and aggregate size increased with pressure, but their measurements were limited to $5 \mathrm{~atm}$. Moreover, fractal and optical properties of soot were assumed to infer soot parameters.

In this study, the primary particle size distribution and fractal properties of soot are reported at elevated pressures in a counterflow diffusion flame. According to our knowledge, thermophoretic sampling and TEM analysis for morphological properties of soot in pressurized counterflow flames has not been reported in archival literature. A pneumatic thermophoretic sampling device is set up for inflame soot sampling in pressurized flames. $N_{2}$-diluted ethylene air counterflow flames are stabilized at various pressures from 3 to $10 \mathrm{~atm}$ and soot samples are collected on TEM grids. These grids are then 
analyzed under transmission electron microscope to infer the primary particle size distribution, fractal dimension $\left(D_{\mathrm{f}}\right)$ and fractal prefactor $\left(k_{\mathrm{f}}\right)$ of soot.

\section{Experimental Setup}

The counterflow burner used in [15] is slightly modified for the present study. It consists of two opposing straight ducts with internal diameters of $8.5 \mathrm{~mm}$. A separation distance $(H)$ of $8 \mathrm{~mm}$ between the two nozzles is kept constant throughout the study. Ethylene (diluted with nitrogen) is supplied from the bottom side while air is supplied from the top side, and both streams have equal momentums. The global strain rate $(a)$, defined as the mean exit velocity of air divided by half of the separation distance between fuel and oxidizer nozzles [13], is maintained at $30 \mathrm{~s}^{-1}$ at all pressures by adjusting the inlet mass flux. A shroud flow of nitrogen is provided through the outer nozzles to prevent entrainment. Due to the desire for a minimal sampling time in this setup, the fuel mole fraction $\left(X_{\mathrm{f}}\right)$ is adjusted to control soot loading in order to avoid the overlapping of soot aggregates on TEM grids. All flames studied are soot formation flames, and their stoichiometric mixture fraction $Z_{\mathrm{st}}=0.253,0.184$ corresponding to fuel mole fractions of 0.2 and 0.3 , respectively. Mainstream flow rates at all pressures are provided in table 1.

Table 1

Volumetric flow rates of main streams

\begin{tabular}{ccccc}
\hline \multirow{2}{*}{$X_{\mathrm{f}}$} & \multirow{2}{*}{$\begin{array}{c}\text { Pressure } \\
\text { [atm] }\end{array}$} & \multicolumn{3}{c}{ Flow rates [slpm] } \\
\cline { 3 - 5 } 0.3 & 3 & 1.22 & 0.37 & 0.87 \\
& 5 & 2.04 & 0.62 & 1.45 \\
& 6 & 2.45 & 0.74 & 1.74 \\
\hline \multirow{3}{*}{0.2} & 5 & 2.04 & 0.41 & 1.65 \\
& 7 & 2.86 & 0.58 & 2.31 \\
& 10 & 4.08 & 0.83 & 3.31 \\
\hline
\end{tabular}


The counterflow burner is enclosed in a pressure vessel, details of which are available in [18]. A schematic of the sampling device connected to the pressure vessel is shown in Fig. 1. For our study, we designed and built a thermophoretic sampling device based on the pneumatically driven thermophoretic sampling device for high pressure flames reported by Leschowski et al. [19]. Details of the thermophoretic sampling device are provided below.

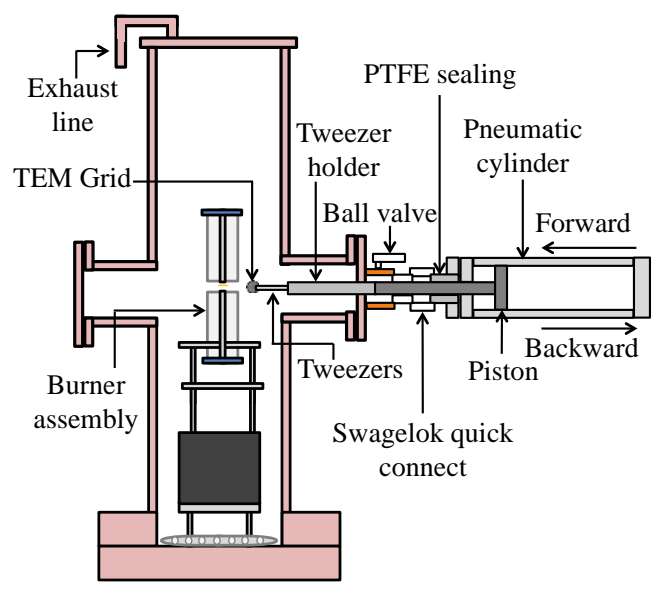

Fig. 1. Schematic of the experimental setup

The sampling device consists of a double-acting pneumatic cylinder with a tweezer holder adaptor attached. Reverse-acting tweezers hold the TEM grid (carbon-coated 300 mesh copper grids $(\mathrm{CF} 300-\mathrm{Cu}))$ parallel to the axis of the flame. To move the TEM grid into the pressure vessel, air is supplied to the pneumatic cylinder, at a maximum pressure of 12 bar. Once the TEM grid moves through the flame (forward direction), the flow of fuel is turned off to extinguish the flame. A highspeed camera (FASTCAM-ultima APX 120K) is triggered just before opening the air inlet valve of the pneumatic cylinder. Images are taken at $6000 \mathrm{fps}$ to capture the sampling process. The TEM grid is then retracted from the vessel and stored. One of the shortcomings of using thermophoretic sampling is that flame flow fields are disturbed during the sampling. The intrusion of the sampling probe can affect the sampling results, but this interference is mostly assumed to be hydrodynamic [20]. Quantifying the effects of flow field disturbances on the sampling process is difficult. However, in the flames presented 
in this study, our sampling method produces visually negligible disturbances in the flame. The sampling time varies from $29 \mathrm{~ms}$ (at $10 \mathrm{~atm}$ ) to $44 \mathrm{~ms}$ (at $6 \mathrm{~atm}$ ) depending on the flame length and pressure. Figure 2 shows the sequence of images of sampling at $5 \mathrm{~atm}$. Some oscillations of the soot zone in the radial direction are observed, but these were minimized as much as possible. At $t=0$, the grid enters the visible boundary of the soot zone from the right and exits the flame on the left side. The flame is then extinguished and the grid is removed for analysis. Thus, the grid only passes through the flame one time.

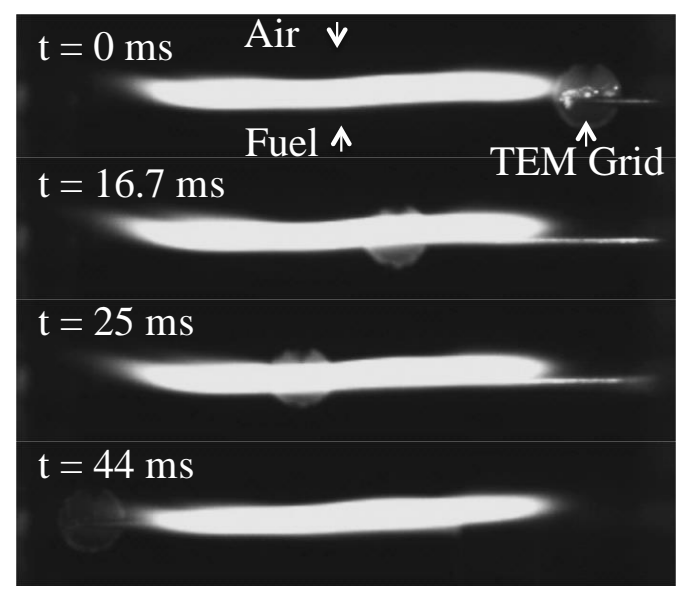

Fig. 2. Images of flame during sampling process

\section{TEM image analysis}

\subsection{Primary particle size}

Before collecting soot samples, TEM grids are marked on the edge (near the air stream) and the high speed images captured during sampling allow us to locate the area of the grid on which soot is collected. The soot zone in counterflow flames, where all soot growth occurs, is approximately $1 \mathrm{~mm}$ thick. Due to the slight curvature of the soot zone and the lack of information on the exact location of the soot aggregates sampled on TEM grids, it is not possible to investigate the spatial distribution of soot properties. This is why the images are recorded by scanning the TEM grid at different areas under TEM (Tecnai Spirit Twin: FEI). This allows us to investigate several parameters of interest of the entire counterflow flame at different pressures. For particle size distribution, images are recorded at 
magnifications of $30,000 x$ to $42,000 x$ by scanning different areas on the TEM grid. ImageJ is an open source software that was used for image processing. Following the procedure given in [21], we calculate the particle size distribution manually by detecting the circular boundaries of clear particles.

\subsection{Analysis of fractal properties of aggregates}

For aggregate fractal properties, images are taken at magnification of $6,500 \mathrm{x}$ to $11,000 \mathrm{x}$. The procedure for calculating the 3D fractal properties of soot from their 2D projections is detailed in [7, 22]. The number of primary particles in an aggregate $(N)$ can be estimated using the following empirical correlation:

$$
N=k_{a}\left[\left(\frac{A_{a}}{\pi \overline{d_{p}^{2}} / 4}\right)\right]^{\alpha}
$$

where $A_{\mathrm{a}}$ is the projected area of an aggregate and $\overline{d_{p}}$ is mean diameter of primary particle. These parameters are estimated by analyzing the TEM images using ImageJ. $k_{\mathrm{a}}$ and $\alpha$ are empirical constants and their values are 1.15 and 1.09 based on extensive morphological analysis in [23]. According to mass fractal relationship, the number of primary particles in an aggregate is related to the fractal properties by the following relationship:

$$
N=k_{f}\left(2 R_{g} / d_{p}\right)^{D_{f}}
$$

where, $D_{\mathrm{f}}$ and $k_{\mathrm{f}}$ are the fractal dimension and fractal prefactor of aggregates. $R_{\mathrm{g}}$ is the radius of gyration of an aggregate and cannot be measured directly from TEM images. Equation (2) can be written in the form of maximum length $(L)$ of an aggregate:

$$
N=k_{L}\left(L / \overline{d_{p}}\right)^{D_{f}}
$$

where $k_{\mathrm{L}}$ is the projected aggregate prefactor parameter. The fractal dimension is calculated by defining the slope of the data on the log-log plot of $N$ vs $L / \overline{d_{p}}$. The fractal prefactor is calculated using the following relation: 


$$
\frac{k_{f}}{k_{L}}=\left(\frac{L}{2 R_{g}}\right)^{D_{f}}=\left(\frac{D_{f}+2}{D_{f}}\right)^{D_{f} / 2}
$$

\section{Results and discussion}

\subsection{Particle size distribution}

TEM images of aggregates at different pressures are shown in Fig. 3. As pressure increases, particles become more opaque with more distinguishable boundaries. Non-spherical particles also seem to form due to coalescence processes.

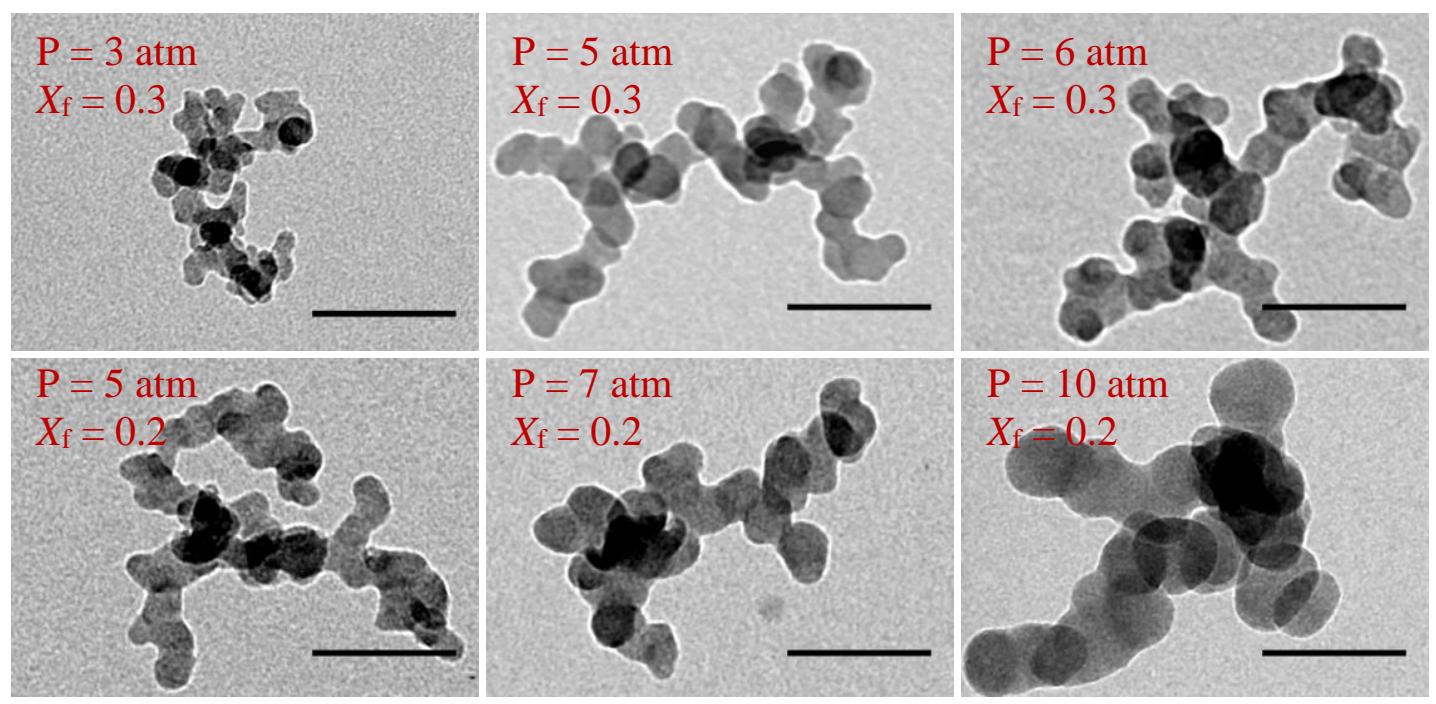

Fig. 3. TEM images of soot aggregates at magnification of 30000 to 42000 . Scale bar length is $100 \mathrm{~nm}$.

Primary particle size distributions are obtained by measuring at least 430 primary particles, at each pressure. Primary particle size distributions with fitted lognormal distribution at different pressures are shown in Fig. 4. Pressurized flames show an increase in mean particle diameter $\left(\overline{d_{p}}\right)$ with very little variations due to the fuel mole fraction at 5 atm. $\overline{d_{p}}$ scales with pressure to a power of 0.82 , when fitted to power law. Geometric width $\left(\sigma_{\mathrm{p}, \mathrm{g}}\right)$ of particle size distribution is small and the primary particles are nearly monodispersed. Several sources of uncertainties in these measurements exist. These uncertainties are due to disturbances of the flow field during the sampling process and also from image analysis uncertainties while calculating particle sizes. Although our sampling process minimizes flame 
disturbances, quantifying this uncertainty is not possible. We estimate the degree of uncertainty of image analysis to be less than $10 \%$ (95\% confidence interval).
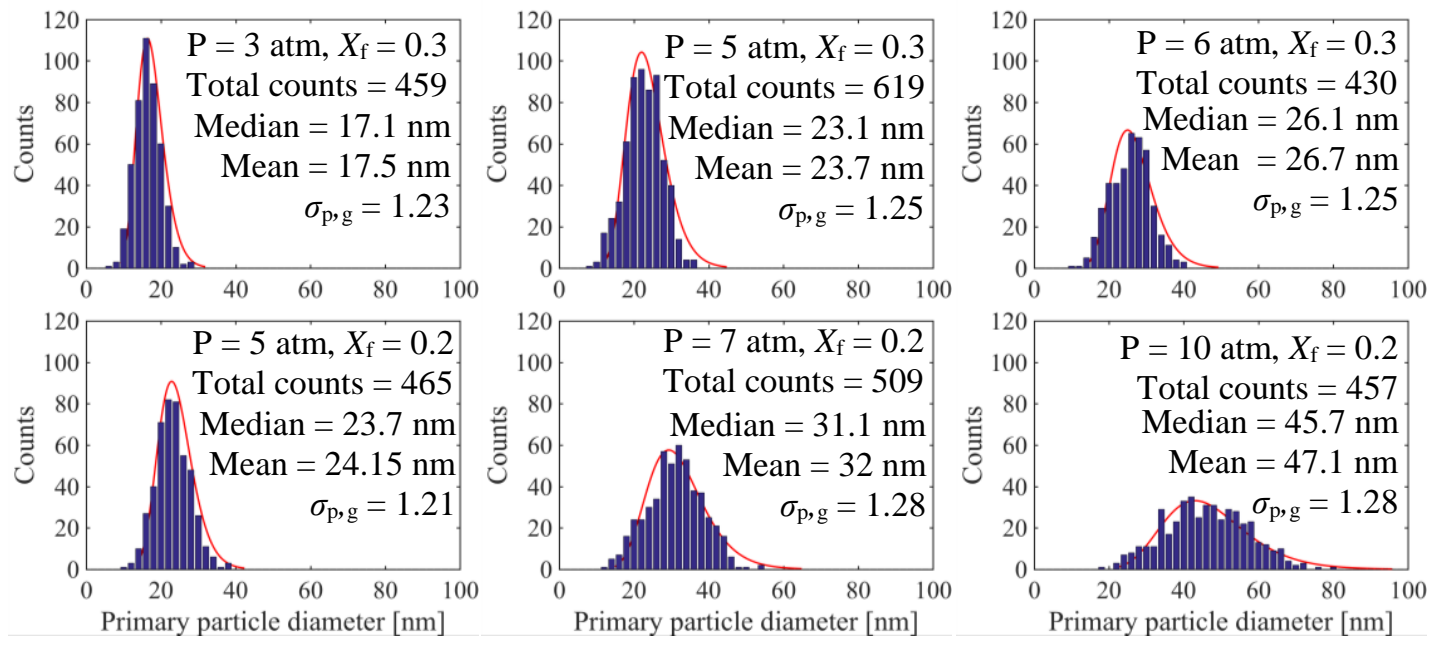

Fig. 4. Primary particle size distribution in pressurized flames

In a recent study by Joo et al. [24], the pressure dependence of primary particle size in ethylene air coflow flames is reported up to 20 atm. They found that the mean primary particle size increased up to $15 \mathrm{~atm}$ and at $20 \mathrm{~atm}$ the diameter reached a plateau or started to decrease. In their study, measurements were averaged over the cross-section of the flame, at each sampling height above the burner.

\subsection{Aggregate Fractal properties}

TEM images of aggregates at different pressures are shown in Fig. 5. The images clearly show that soot aggregates in each flame are polydisperse, with a wide distribution, whereas primary particles at each pressure are nearly monodisperse with small geometric width $\left(\sigma_{\mathrm{p}, \mathrm{g}}\right)$ as reported in Fig. 4 . TEM images also show the presence of single particles, which are less opaque. Aggregates with fewer than three primary particles are not considered in the analysis as they do not follow the mass fractal relationship [25]. At each pressure, 600 to 1400 aggregates are analyzed for calculating their fractal properties. These measurements have shown very good reproducibility when analyzing different samples under same operating conditions. Result details of two different samples at 5 atm are provided in the supplementary material. Although, experimental uncertainties exist due to the consideration of a 
sample of finite size, thermophoresis dependency on soot parameters and analysis of 2D images for inferring the information of $3 \mathrm{D}$ structure of soot, this technique has been successfully used for investigating the fractal properties of soot $[21,22,26]$.

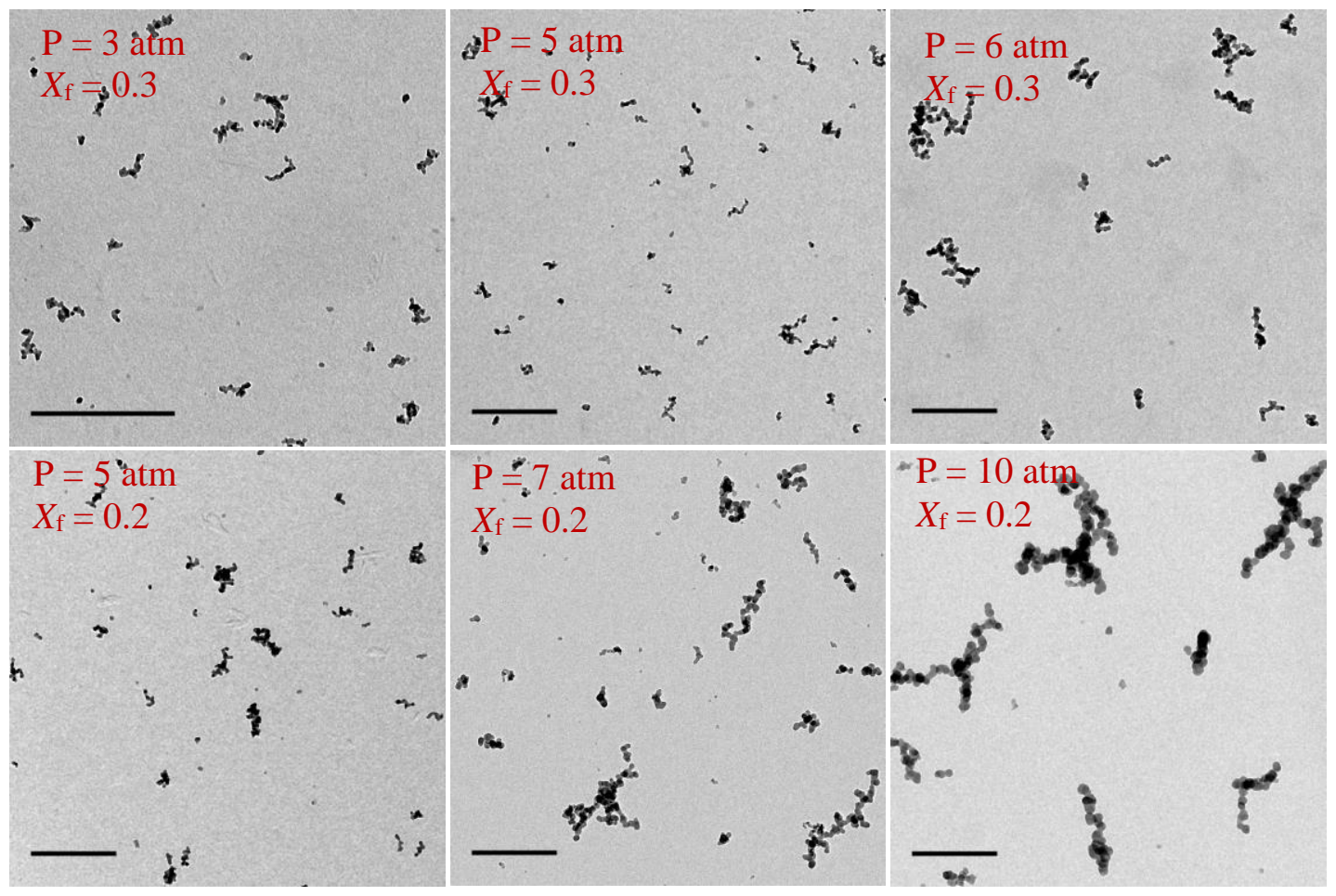

Fig. 5. TEM Images of soot aggregates at magnification of 6500 to 11000 . Scale bar length is $500 \mathrm{~nm}$.

TEM images for fractal properties of soot aggregates are analyzed using the method described in section 3.2. Number of primary particles in an aggregate is calculated using Eq. (1). Aggregate size distribution parameters for an entire flame, at each pressure, are calculated using the number of monomers per aggregate and are reported in table 2 while their plots are provided in supplementary material.

Table 2

Aggregate size distribution parameters

\begin{tabular}{c|cccccc}
\hline & \multicolumn{3}{|c|}{$X_{\mathrm{f}}=0.3$} & \multicolumn{3}{c}{$X_{\mathrm{f}}=0.2$} \\
\hline $\mathrm{P}[\mathrm{atm}]$ & 3 & 5 & 6 & 5 & 7 & 10 \\
\hline$N_{\mathrm{g}}$ & 10.2 & 12.8 & 15.9 & 12.4 & 13.6 & 12.09 \\
$\sigma_{\mathrm{N}, \mathrm{g}}$ & 2.28 & 2.5 & 2.56 & 2.53 & 2.7 & 2.52 \\
\hline
\end{tabular}


$\sigma_{\mathrm{N}, \mathrm{g}}$ is the geometric width and $N_{\mathrm{g}}$ is the geometric mean of aggregate size distribution. Both parameters do not seem to follow a particular trend with pressure.
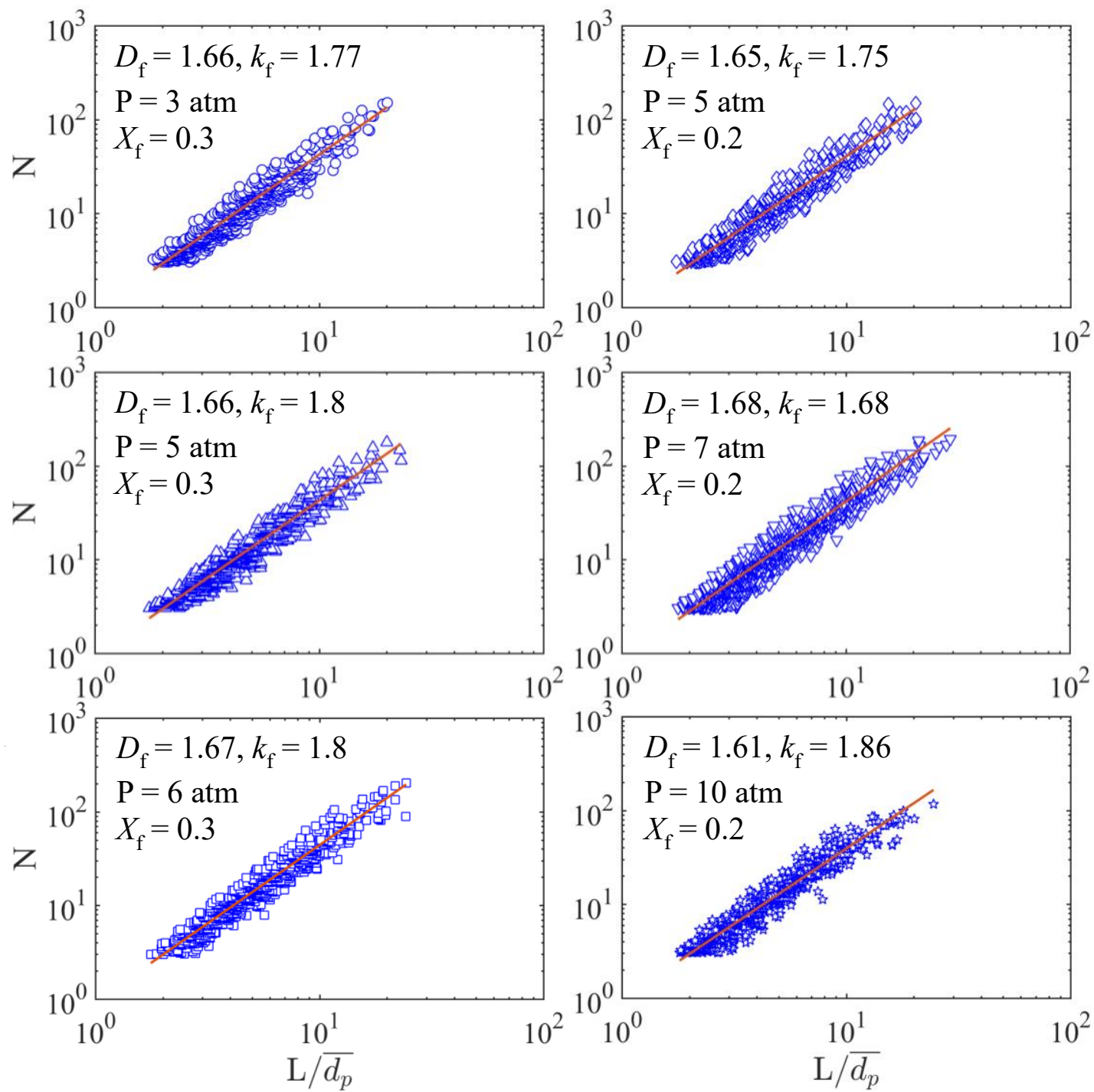

Fig. 6. Log-log plot of $N$ vs $L / \overline{d_{p}}$ for aggregates in pressurized counterflow flames

Figure 6 shows the scatter plot of the number of primary particles in an aggregate vs. nondimensional maximum aggregate size. A linear fit to the $\log -\log$ plot of $L / \overline{d_{p}}$ vs $N$ is performed using the MATLAB routine available at [27] which follows the method of [28]. The slope and intercept of linear regression provide information about $D_{\mathrm{f}}$ and $k_{\mathrm{L}}$ and Eq. (4) is used to calculate the fractal prefactor 
of aggregates. From these measurements, the values of $D_{\mathrm{f}}$ and $k_{\mathrm{f}}$ of soot do not seem to change with pressure.

In this work, measurements were performed at constant global strain rate considering the work of Figura et al., [14, 29], where they discuss the choice of experimental conditions. At a constant global strain rate, the particles undergo a nearly identical temperature-time history, which is of paramount importance in soot. However, increasing the mass flux of fuel with pressure also increases the carbon flux, and this effect on morphological parameters is not well understood. In a recent study by Xue et al. [30], they report that soot volume fraction scales faster with pressure in counterflow flames at constant mass flux compared to constant strain rate. In this work, at 5 atm, the variation of $X_{\mathrm{f}}$ from 0.2 to 0.3 results in an increase of carbon flux from $0.0105 \mathrm{~g} / \mathrm{s}$ to $0.0069 \mathrm{~g} / \mathrm{s}$. Thus, at $5 \mathrm{~atm}$, a $50 \%$ increase of carbon flux does not result in an appreciable change in soot particle size (Fig. 4) or fractal properties (Fig. 6). At $7 \mathrm{~atm}$ the carbon flux is $0.0097 \mathrm{~g} / \mathrm{s}$ which is slightly less than the one $0.0105 \mathrm{~g} / \mathrm{s}$ at $5 \mathrm{~atm}$ with $X_{\mathrm{f}}=0.3$. Looking at Fig. 4 and Fig. 6, only particle size has been increased with pressure but no change in fractal properties are reported from 5 to 7 atm. Therefore, particle size may be affected by a change in carbon flux. However, these effects are not significant within the experimental conditions of the present study and have not been captured by TS-TEM analysis. It is therefore suggested that a change in particle size is due only to pressure. Moreover, fractal properties of soot are not seen to be sensitive to changes in pressure or carbon flux. Fractal properties of soot have been reported to be nearly independent of fuel type, flame conditions, sampling locations or operating conditions [7, 23]. Koylu et al. [7] reported a fractal dimension of $1.7 \pm 0.15$ independent of flame conditions and fuel type. A similar value of $1.69 \pm 0.2$ has also been reported in atmospheric laminar coflow flames [31]. Values of fractal dimension of soot in current study range from 1.61 to 1.67 at different pressures with uncertainty of 0.05 (95\% confidence) for the mean value. A thorough search of literature revealed the only information about fractal properties of soot in pressurized counterflow flames was reported in the doctoral thesis of Sarnacki [32], where the measured fractal dimension and fractal prefactor are 1.41 and 2.9, respectively 
at 8.45 atm. Lower fractal dimension and high fractal prefactor of soot may be due to an insufficient number of aggregates analyzed. Fractal prefactor for atmospheric flames has been reported to be in the range of 1.9 to $2.8[21,22,26]$, independently of the flame location. $k_{\mathrm{f}}$ values for this study vary from 1.68 to 1.86 with experimental uncertainty of 0.16 (95\% confidence) and unaffected by a change in pressure

\section{Conclusions}

In this study, we perform thermophoretic sampling in an $N_{2}$-diluted ethylene air counterflow diffusion flames up to 10 atm to investigate the effects of pressure on primary particle size distribution and fractal properties of soot aggregates. To avoid the overlap of soot aggregates on TEM grids, we reduce the soot loading over the range of pressure investigated by varying the fuel mole fractions.

Due to the small thickness of the soot zone in these moderately strained counterflow diffusion flames, it is very difficult to resolve the soot field spatially. The entire soot zone is sampled on the TEM grid, and our sampling procedure causes very little disruption to the flame. From these measurements, we obtain the following results:

- Primary particle diameter increases with pressure and a mean particle diameter of $17.5 \mathrm{~nm}$ at 3 atm increases to $47 \mathrm{~nm}$ at 10 atm. At each pressure, the primary particles are nearly monodisperse. Primary particles with a non-circular 2D projection are also present, which might result from coalescence of small soot particles.

- Observation of TEM images show that, unlike primary particles, soot aggregates are polydisperse. We also observe the presence of single particles and aggregates consisting of up to hundreds of primary particles. Geometric mean of aggregate size distribution vary from 10.2 to 15.9, with no specific dependence on pressure. 
- Fractal dimension of the soot aggregates appears independent of pressure, with its value changing from 1.61 to 1.67 . Fractal prefactor also shows no significant variation at different pressures, and its value ranges from 1.68 to 1.86 for the flames investigated here.

Quantitative morphology measurements of soot at elevated pressure are essential for soot modeling and soot particle size measurements using laser diagnostics by allowing accurate calculation of the scattering to absorption ratio. Such measurements are also useful in understanding the global effects of pressure on morphological parameters of soot in counterflow flames. It is recommended that future work be done to investigate soot morphology over a wider range of fuel mole fractions and strain rates at elevated pressures.

\section{Acknowledgements}

This publication is based upon work supported by King Abdullah University of Science and Technology (KAUST). The authors would like to thank the Imaging and Characterization lab at KAUST for their assistance with the TEM analysis. 


\section{References:}

[1] J. Heinrich, H.-E. Wichmann, Curr. Opin. Allergy Clin. Immunol., 4 (2004) 341-348.

[2] D.M. Broday, R. Rosenzweig, J. Aerosol Sci, 42 (2011) 372-386.

[3] L.H. Van Poppel, H. Friedrich, J. Spinsby, S.H. Chung, J.H. Seinfeld, P.R. Buseck, Geophys. Res. Lett., 32 (2005).

[4] S. Choi, C. Myung, S. Park, Int. J. Automot. Technol., 15 (2014) 219-227.

[5] T.C. Fang, C.M. Megaridis, W.A. Sowa, G.S. Samuelsen, Combust. Flame, 112 (1998) 312-328.

[6] C.M. Sorensen, J. Cai, N. Lu, Appl. Opt., 31 (1992) 6547-6557.

[7] U.O. Koylu, Y. Xing, D.E. Rosner, Langmuir, 11 (1995) 4848-4854.

[8] A.E. Karataş, Ö.L. Gülder, Prog. Energy Combust. Sci., 38 (2012) 818-845.

[9] S.A. Steinmetz, T. Fang, W.L. Roberts, Combust. Flame, 169 (2016) 85 - 93.

[10] K.A. Thomson, D.R. Snelling, G.J. Smallwood, F. Liu, Appl. Phys. B, 83 (2006) 469-475.

[11] A.M. Vargas, Ö.L. Gülder, Proc. Combust. Inst., 36 (2016) 975-984.

[12] M.D. Smooke, M.B. Long, B.C. Connelly, M.B. Colket, R.J. Hall, Combust. Flame, 143 (2005) 613-628.

[13] C. J. Sung, B. Li, H. Wang, C.K. Law, Proc. Combust. Inst. 27, (1998) 1523-1529.

[14] L. Figura, A. Gomez, Combust. Flame, 161 (2014) 1587-1603.

[15] H.M.F. Amin, W.L. Roberts, Proc. Combust. Inst., 36 (2016) 861-869.

[16] U. Niemann, K. Seshadri, F.A. Williams, Proc. Combust. Inst., 34 (2012) 881-886.

[17] R.K. Gehmlich, A. Kuo, K. Seshadri, Proc. Combust. Inst., 35 (2015) 937-943.

[18] R.K.A. Kailasanathan, Experimental Investigations on Ethylene Laminar Flames at Elevated Pressures, PhD thesis, North Carolina State University, NC, USA, 2012.

[19] M. Leschowski, T. Dreier, C. Schulz, Rev. Sci. Instrum., 85 (2014) 045103.

[20] J. Lee, I. Altman, M. Choi, J. Aerosol Sci, 39 (2008) 418-431.

[21] Ü.Ö. Köylü, C.S. McEnally, D.E. Rosner, L.D. Pfefferle, Combust. Flame, 110 (1997) 494-507. 
[22] B. Hu, B. Yang, U.O. Koylu, Combust. Flame, 134 (2003) 93-106.

[23] U.O. Koylu, G.M. Faeth, T.L. Farias, M.G. Carvalho, Combust. Flame, (1995) 621-633.

[24] P.H. Joo, M. Christensen, E.A. Griffin, B. Gigone, Ö.L. Gülder, Soot primary particle size dependence on combustion pressure in laminar ethylene diffusion flames, paper presented at the 10th Mediterranean Combustion Symposium, Napoli, Italy (2017).

[25] K. Kondo, T. Aizawa, S. Kook, L. Pickett, Uncertainty in sampling and TEM analysis of soot particles in diesel spray flame, SAE International, SAE world congress, Detroit, USA, 2013.

[26] B. Hu, U.O. Koylu, Aerosol Sci. Technol., 38 (2004) 1009-1018.

[27] T. Wiens, available at <https://www.mathworks.com/matlabcentral/fileexchange/26586-linearregression-with-errors-in- $x-$ and-y>.

[28] D. York, N.M. Evensen, M.L. Martínez, J. De Basabe Delgado, Am. J. Phys, 72 (2004) 367-375.

[29] L. Figura, F. Carbone, A. Gomez, Proc. Combust. Inst., 35 (2015) 1871-1878.

[30] X. Xue, P. Singh, C.-J. Sung, Combust. Flame, 195 (2018) 253-266.

[31] N.J. Kempema, M.B. Long, Combust. Flame, 164 (2016) 373-385.

[32] B. Sarnacki, Pressure and flow residence time effects on soot properties in counterflow nonpremixed hydrocarbon-air flames, PhD thesis, University of Virginia, USA, 2014. 


\section{Tables}

Table 1: Volumetric flow rates of main streams

Table 2: Aggregate size distribution parameters

\section{Figures}

Fig. 1. Schematic of the experimental setup

Fig. 2. Images of flame during sampling process

Fig. 3. TEM images of soot aggregates at magnification of 30000 to 42000 . Scale bar length is $100 \mathrm{~nm}$.

Fig. 4. Primary particle size distribution in pressurized flames

Fig. 5. TEM Images of soot aggregates at magnification of 6500 to 11000 . Scale bar length is $500 \mathrm{~nm}$.

Fig. 6. Log-log plot of $N$ vs $L \overline{d_{p}}$ for aggregates in pressurized counterflow flames

\section{Supplemental Material}

Fig. S1. Log-log plot of $N v s L \overline{d_{p}}$ for aggregates analyzed from different samples at similar operating conditions

Fig. S2. Aggregate size distribution in pressurized flames 